\title{
TRIBOLOGICAL PERFORMANCE OF REFINED, BLEACHED AND DEODORISED PALM OLEIN BLENDS BIO-LUBRICANTS
}

\author{
MOHAMMED HASSAN*; FARID NASIR ANI ${ }^{\star *}$ and S SYAHRULLAIL**
}

\begin{abstract}
Vegetable oils have been investigated to replace petroleum lubricants due to their environmental-friendly characteristics and have become a vital source of bio-lubricants. In the investigation of the tribological characteristics of palm oil as the vegetable oil, using in its neat form or as partial bio-lubricants, a reciprocating machine was employed. Initially, refined, bleached and deodorised (RBD) palm olein with mineral oil blends were optimised using the design of experiments procedure from the outcomes of the four ball tribotester. The optimised blend was found to have characteristics that were better or at par with mineral oil. Then, a reciprocating machine was used for verifying the blend. In the investigation of the optimised blend, the sample was tested for a total of $60 \mathrm{hr}$ in intermittent operation. Other than having similar viscosity for the ISO requirements, the optimised blend demonstrates decreased in the values of material weight loss and cylinder temperatures as compared with mineral oil. Finally, it is concluded that the RBD palm olein blend (E53.11/RB46.89) could be a potential partial bio-lubricant due to having no negative impact on wear and decent performance as a bio-lubricator.
\end{abstract}

\section{Keywords: RBD palm olein, tribology characteristics, reciprocating air compressor, bio-lubricant, wear (weight) losses.}

Date received: 14 March 2016; Sent for revision: 25 May 2016; Received in final form: 9 August 2016; Accepted: 20 October 2016.

\section{INTRODUCTION}

Lubrication is very important in the industrial world, where it is widely used in transportation and in all machinery. Lubricant is used in order to reduce the friction between two moving surfaces or reduce the metal to metal contact (Duzcukoglu and Şahin, 2010). The current rates of biodegradable lubricants production make only a fraction of the total production of lubricants. Base oil makes up over $90 \%$ of a lubricant and the additive package makes the remaining $10 \%$. The base oil employed

\footnotetext{
* Electromechanical Engineering, University of Technology, Baghdad, Karda, Iraq.

** Faculty of Mechanical Engineering, Universiti Teknologi Malaysia, 81310 UTM Skudai, Johor, Malaysia. E-mail: farid@mail.fkm.utm.my
}

in most formulations includes mineral oil, which is environmentally reactive. Hence, exploring ways to substitute the mineral oils with more eco-friendly options has become a primary concern of researchers in the lubricant industry (Bartz, 2006).

Better intrinsic lubrication features are observed in the long chain fatty acids and the large amount of unsaturated and polar ester groups present in vegetable oils (Petlyuk and Adams, 2004). These oils are able to offer great lubrication because they help in minimising the coefficients of friction. However, it has also been reported by many researchers that most vegetable oils have a lower friction coefficient and higher rate of wear (Golshokouh et al., 2014). Many studies have been performed on engineering applications of vegetable oils under headings like the potential of vegetable oils as lubricants, hydraulic fluids, and used as an additive (Wan Nik et al., 2005; 2007; 2013; Ing et al., 2012; Mohammed 
Hassan et al., 2015; Jabal et al., 2014), most of these works indicated to the low wear resistance and thermal stability.

There is little published work on the effect of vegetable oil on the lubricated wear behaviour of piston rings, cylinder liners, and other moving parts in the reciprocating machine. Sivasankaran et al. (1988) have performed lubricated wear experiments using jojoba oil as the base lubricating oil in a twostroke gasoline engine. Rewolinski ( 1985a, b) has conducted lubricated wear experiments using blended diesel lubricating oil with sunflower oil fuel. Masjuki (1992) has also performed experiments on the lubricated wear of cast iron using POD as a lubricating oil additive. Masjuki and Maleque (1996) studied the wear resistance of piston rings with palm oil methyl ester (POME) blending lubrication, which was found to be greater than the pure commercial oil lubrication. Other results indicated that the POME acts as an additive, which improves the engine performance and exhaust emissions of two-stroke gasoline engines.

By employing the air compressor machine and the four-ball tribotester compliance with the ASTM D4172-B Standard, the wear behaviour characteristics and tribological performance were examined in terms of kinematic viscosity, coefficient of friction, wear scar diameter (WSD) and flash temperature parameter.

\section{EXPERIMENTAL METHOD}

\section{Experimental Apparatus}

Initially, the tribological characteristics of the neat RBD palm olein, blends of refined, bleached and deodorised (RBD) palm olein with mineral engine oil, and clean mineral engine oil were evaluated using the four-ball tribotester compliance with the ASTM D4172-B Standard. After that, the use of design of experiments (DOE) to determine the optimisation blend, using on the values of the WSD, friction torque, coefficient of friction, and the flash temperature parameter from the initial experiments.
In the last stage, the tribological performance characteristics for the neat RBD palm olein, optimised blend of RBD palm olein with mineral engine oil, and mineral engine oil were evaluated using a two-piston, single-stage, electrically driven reciprocating air compressor (SWAN SVP-202). These three samples of lubricant, have been tested for a total of $60 \mathrm{hr}$ on intermittent operation conditions using the air compressor system in obtaining the material particles weight loss of the contact moving parts (piston rings, cylinder, crankshaft, and piston rod) and cylinder surface temperatures.

\section{Lubricants}

The lubricants used in this study were RBD palm olein (E0/RB100) and mineral engine oil (E100). The blends of RBD palm olein with the mineral engine oil used, with the volumetric blending ratio of $20 \%$, $40 \%, 60 \%$, and $80 \%$, as shown in Table 1 .

\section{Kinematic Viscosity}

Viscosity is a property of liquids used to define the internal resistance offered by a liquid against flow. It directly affects the thickness of the liquid, along with the rate of wear of the surface on which the liquid is being rubbed. For measuring the viscosity of the lubricants under testing, a rotation viscometer was used. A spindle within the viscometer rotates at a particular speed. Once the spindle is inserted into the emollient, the speed of the spindle is offered resistance by the viscosity of the lubricant.

\section{Wear Surface Characteristics}

Optical as well as high resolution scanning electron microscope was used to study the wear characteristics of the worn surface and the WSD on the three ball bearings were obtained after the experiments were completed. The micrograph images captured through the microscopes were used to find out the diameter of the wear scars and the average of the values was determined.

TABLE 1. VOLUMETRIC BLENDING RATIOS DETAILS OF OIL SAMPLES

\begin{tabular}{|c|c|c|c|c|}
\hline No. & Oil group & Oil type & Oil code & Volumetric blending ratio \\
\hline 1 & Edible vegetable & RBD palm & $\mathrm{E} 80 / \mathrm{RB} 20$ & $80 \%$ Mineral oil $(10 \mathrm{~W}-30)+20 \%$ RBD palm olein \\
\hline 2 & oils & olein & $\mathrm{E} 60 / \mathrm{RB} 40$ & $60 \%$ Mineral oil $(10 \mathrm{~W}-30)+40 \%$ RBD palm olein \\
\hline 3 & & & $\mathrm{E} 40 / \mathrm{RB} 60$ & $40 \%$ Mineral oil $(10 \mathrm{~W}-30)+60 \%$ RBD palm olein \\
\hline 4 & & & E20/RB80 & $20 \%$ Mineral oil (10W-30) $+80 \%$ RBD palm olein \\
\hline 5 & & & E0/RB100 & $0 \%$ Mineral oil $(10 \mathrm{~W}-30)+100 \%$ RBD palm olein \\
\hline 21 & Mineral oil & SAE (10W-30) & E100 & 100\% Mineral oil (10W-30) \\
\hline
\end{tabular}

Note: RBD - refined, bleached and deodorised. 


\section{Friction Torque and Coefficient of Friction}

The friction torque was used as a parameter to calculate the resistance of contact amongst metals. It is also needed in the calculation of the value of the coefficient of friction $(\mu)$, This data can be directly fed into the Winducom software from the four ball tribotester machine. The ratio of the force which maintains contact within the object and the force of friction which resists the speed of the object is represented by the coefficient of friction. This can be calculated by using the following equation (Husnawan et al., 2007):

$$
\mu=\frac{T \sqrt{6}}{13 W r}
$$

where $W$ is the apply loads in $\mathrm{kg}, T$ is the friction torque in $\mathrm{kg} \mathrm{mm}$, and $(r=3.67 \mathrm{~mm})$ is the distance between the rotation axis and the centre of the contact surface on the balls placed at the bottom.

\section{Flash Temperature Parameter}

Flash temperature parameter (FTP) is a dimensionless number used for stating the critical flash temperatures when the emollients will fail to work under given conditions. The probability of degeneration of the lubricant films can be observed through the FTP (Masjuki and Maleque, 1997). A high value of FTP demonstrates higher lubricant performance.

The following equation can be used for measuring FTP (Husnawan et al., 2007):

$$
F T P=\frac{W}{W /(W S D)^{1.4}}
$$

where $W$ is the applied load in $\mathrm{kg}$ and WSD is the wear scar diameter in $\mathrm{mm}$.

\section{Design of Experiments (DOE)}

The optimisation of RBD palm olein and mineral oil blend (volumetric blending ratio) and the correlation between factors, such as friction coefficient, diameter of wear scar, torque of friction, flash temperature parameter, and volumetric blending ratio were determined using a data analysis that used the DOE method. In this section, every set of experiments used was based on ASTM D4172-B Standard.

\section{Wear (weight) Losses}

A two-piston, single-stage reciprocating air compressor (SWAN SVP-202) was used in the experiment to evaluate the tribological performance characteristics is shown in Figure $1 a$.
The air compressor reciprocating machine was used because it uses the mineral oil (SAE 10W-30) during its normal operation and for the purpose of this investigation, the machine was used for comparison. The weight of the particle losses of the moving parts in the machine was measured using method developed by Masjuki and Maleque (1996).

\section{Cylinder Surface Temperatures}

The cylinder surface temperatures of the air compressor were measured using digital thermocouple reader. Two thermocouples were used for the test, each one fixed on the cylinder body, as shown in Figure 1b. For measuring the temperatures of the air compressor cylinder surface, a scanning thermocouple reader was used (Model 9280005/230 VAC50/60Hz-Barnant Co. Barrington, IL 60010). For the measurement of cylinder surface temperatures of the air compressor, the average of the two cylinder surface temperatures during the $360 \mathrm{~min}$ of daily continuous operation time (30 $\mathrm{min}$ intervals) was recorded.

The variation of pressure for different oil samples was controlled using a pressure gauge and pressure valve at $80 \pm 3$ psi. Tests were conducted using $1000 \mathrm{ml}$ each of the three oil samples (neat, mineral, and blends). After the end of the test period of $60 \mathrm{hr}$ for all oil samples, they were discharged through the drain valve using clean containers for storage. After proper shaking of each oil sample, 100 $\mathrm{ml}$ of the homogeneous oil samples were placed into smaller containers and sent for the metallic particle lost weight analysis. The analysis consists of the following apparatus, as shown in Figure 2:

- membrane filter: $47 \mathrm{~mm}$ nitro-cellulose, 0.45 $\mu \mathrm{m}$;

- forceps borosilicate filter holder: millipore XX10047005, available from Millipore Corp, Bedford MA, 01273;

- borosilicate filtering flask: Millipore XX1004705, available from Millipore Corp, Bedford MA, 01273;

- wash bottle vacuum source: capable maintaining a vacuum of $71 \mathrm{kPa} \pm 5 \mathrm{kPa}$

- beaker: $250 \mathrm{ml}$; and

- electronic digital balance: an accuracy of $0.001 \mathrm{mg}$.

\section{RESULTS AND DISCUSSION}

The tribological characteristics and the practical performance for the oil samples, which were adopted in this research, were investigated and characterised, using the four-ball tribotester compliance with the ASTM D4172-B Standard and the air reciprocating compressor system, running for $60 \mathrm{hr}$ in intermittent operation. The kinematic 

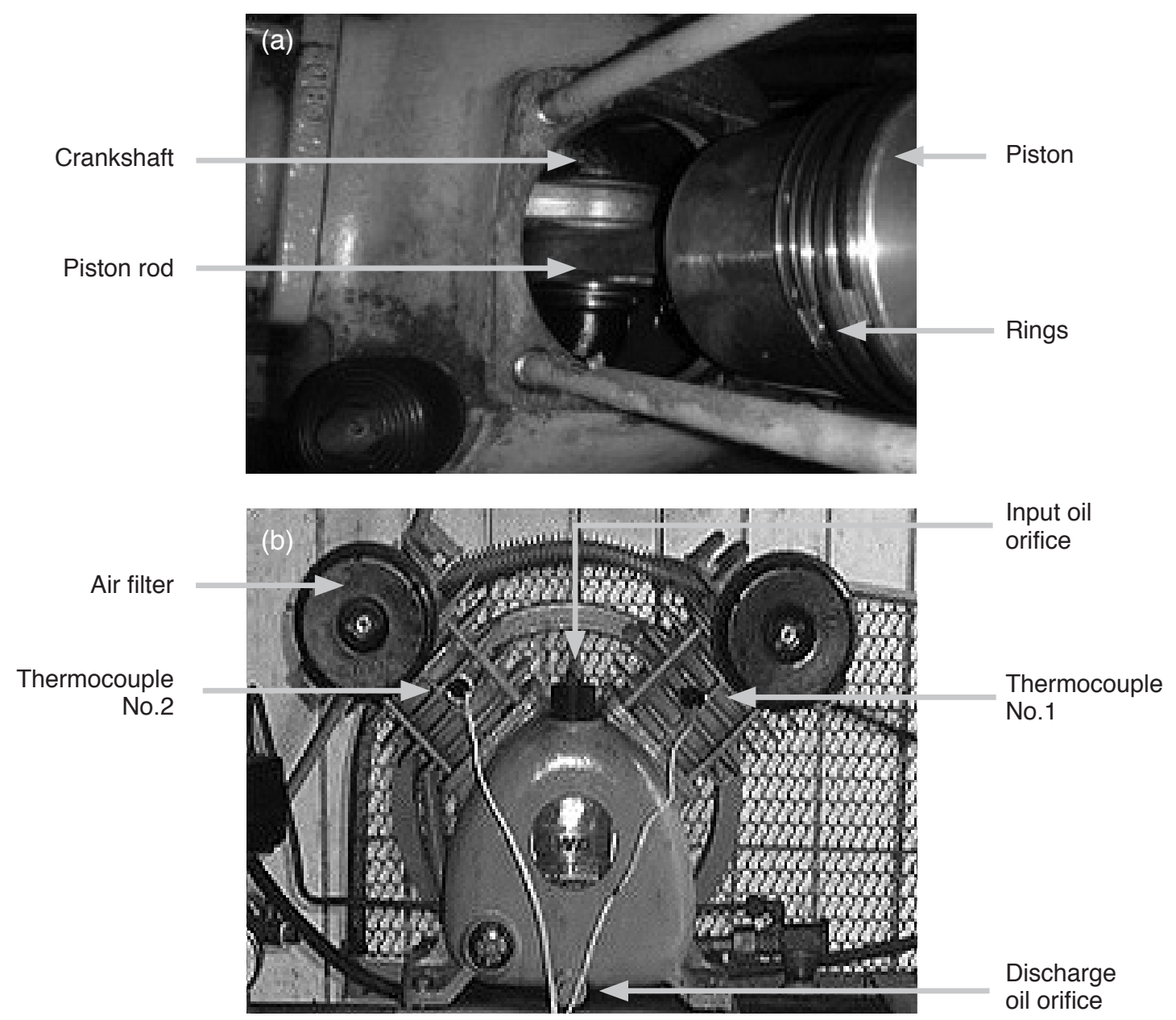

Figure 1. (a) Moving parts (piston rings, crankshaft, and piston rod); (b) thermocouples fixing position on the cylinder body of the machine.

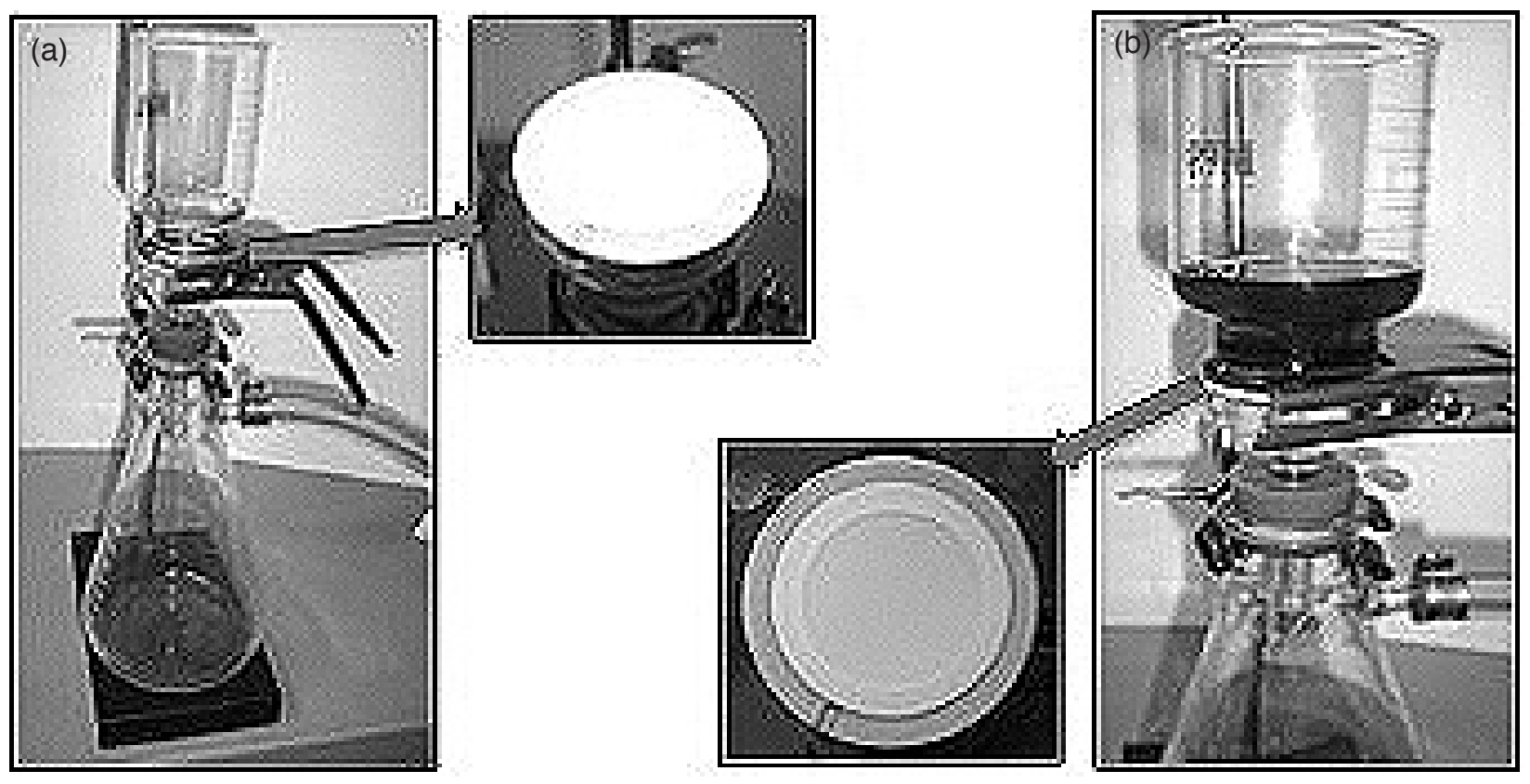

Figure 2. Metallic particle lost weight apparatus: (a) before test; (b) after test. 
viscosity, WSD, friction torque and coefficient of friction, FTP, cylinder surface temperatures, and the metallic particle lost weight of the contact moving parts were used as a comparison factors between the oil samples.

\section{Kinematic Viscosity}

The comparison of kinematic viscosities for RBD palm olein with mineral oil blends under varying temperatures, namely $40^{\circ} \mathrm{C}, 75^{\circ} \mathrm{C}$, and $100^{\circ} \mathrm{C}$, are illustrated in Figure $3 a$. The figure provides an illustration that the kinematic viscosity for RBD palm olein and mineral oil blends reduce when temperatures increase. In addition, a similar outcome involving viscosity reduction through temperature increments was obtained by several researchers (Shahabuddin et al., 2013; Masjuki et al., 2011).

Furthermore, the figure indicates that under higher temperatures, the comparison shows the viscosity quantities of all oils were comparable to each other. The highest kinematic viscosity quantity at $40^{\circ} \mathrm{C}$ was $79 \mathrm{~mm}^{2} \mathrm{~s}^{-1}$, which was obtained for RBD palm olein blend (E80/RB20), compared to neat RBD palm olein at $33.8 \mathrm{~mm}^{2} \mathrm{~s}^{-1}$ and mineral engine oil at $42.8 \mathrm{~mm}^{2} \mathrm{~s}^{-1}$. However, the lowest viscosity quantity acquired at $100^{\circ} \mathrm{C}$ for the neat RBD palm olein (E0/RB100) stands at $9.8 \mathrm{~mm}^{2} \mathrm{~s}^{-1}$, as compared to that for mineral engine oil at $11.2 \mathrm{~mm}^{2} \mathrm{~s}^{-1}$.

The viscosity index quantity for neat RBD palm olein, blends of RBD palm olein with mineral oil, and mineral oil are shown in Figure 3b. From the figure, it could be seen that the neat RBD palm olein value is higher at 296.9, as compared to 267.6 for mineral engine oil. The lowest viscosity index quantity obtained for the blend of E80/CC20 is
113.5. Additionally, based on the obtained results, the viscosity index quantity is reduced through a blending process; however, all the values surpass the viscosity index requirement (Rudnick, 2006).

\section{Wear Surface Characteristics}

The ball specimen outcomes for blends of RBD palm olein and mineral oil are illustrated in Figure 4. The figure indicates different abrasive wear forms, for instance, various scar depths and unbalanced grooves were identified on the surfaces of the balls. Parallel grooves may be observed alongside different depths on the abraded surface because of rough particulate debris, which culminated in abrasion wear (Singh and Gulati, 1991).

Based on Figure $4 a$, the wear scars for all blending ratios of RBD palm olein and mineral oil were circular in shape. The notion that the blending of RBD palm olein and mineral oil reduces the diametric wear scar value more than the neat RBD palm olein as well as the mineral oil is indicated in Figure $4 a$, because increased the value of the kinematic viscosity, and above that, the fatty acid which might cover the rubbing contact surface fully (Shahabuddin et al., 2013). The lowest amount of the diametric wear scar was $408.46 \mu \mathrm{m}$ identified in E60 / RB40 compared to that for neat RBD palm olein at $660.8 \mu \mathrm{m}$ and that for mineral oil at $546.46 \mu \mathrm{m}$.

\section{Coefficient of Friction}

A comparison for friction coefficient values for blends of RBD palm olein and mineral oil is shown in Figure 5a. Based on the figure, the blending procedure reduced the friction coefficient value more than the neat RBD palm olein as well as the

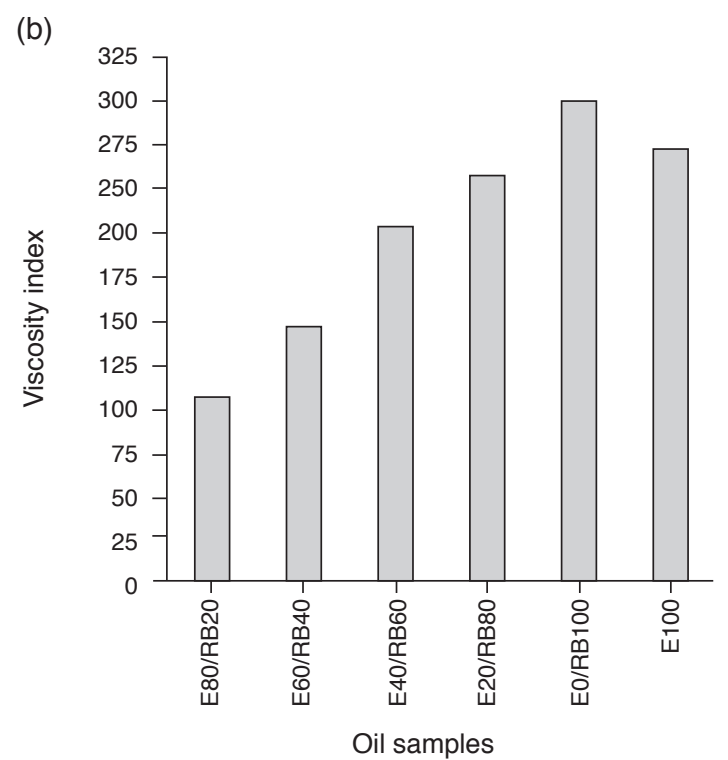



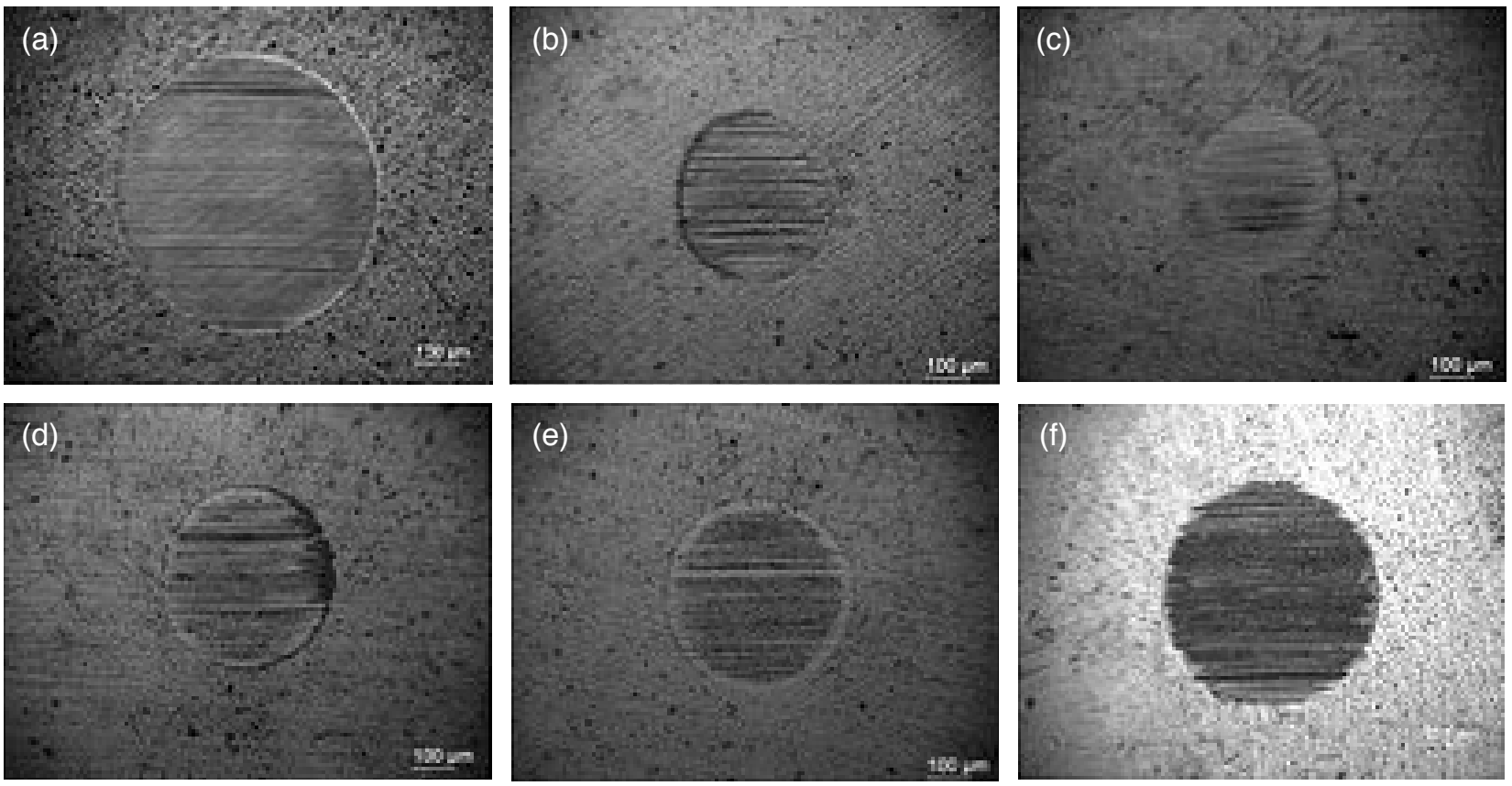

Figure 4. Optical micrographs of refined, bleached and deodorised (RBD) palm olein samples in different volumetric blending ratio: (a) E0/RB100; (b) E80/RB20; (c) E60/RB40; (d) E40/RB60; (e) E20/RB80 and (d) mineral engine oil.

mineral oil, this is due to the long chain fatty acid and the esters of the bio-lubricants, which are known as surface active materials (Masjuki et al., 2011; Shahabuddin et al., 2013). The lowest friction coefficient value was 0.057 for the sample of E60/ RB40 blend compared to that for neat RBD palm olein at 0.072 and that for mineral oil at 0.081 .

\section{Friction Torque}

The data for friction torque (FT) were tabulated from the four-ball tribotester with the help of a computer and presented graphically as shown

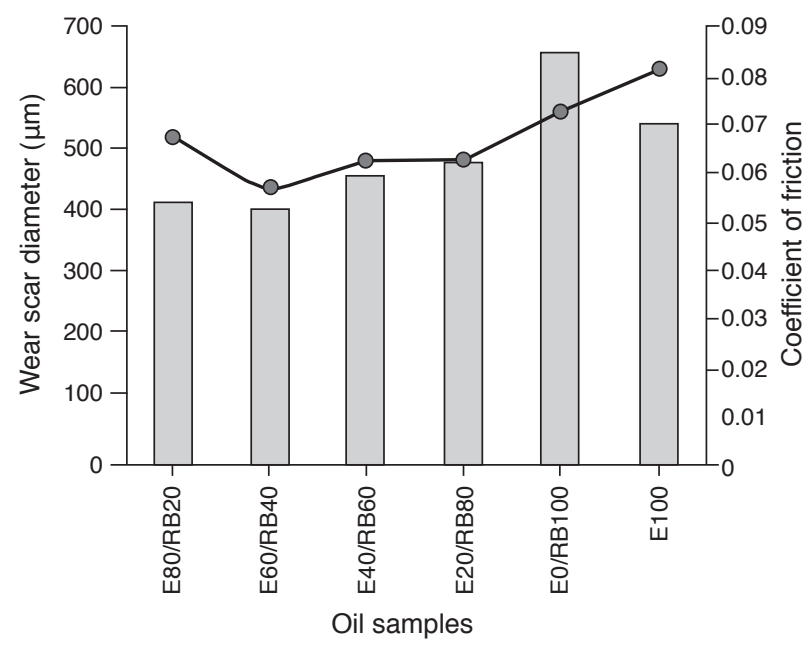

in Figure 5b. The figure compares the FT values for blends of RBD palm olein and mineral oil. As illustrated in the figure, the FT values were reduced by the blending procedure as compared to neat RBD palm olein as well as mineral oil (Shahabuddin et al., 2013). The lowest friction torque value was 0.100 $\mathrm{Nm}$ for the E60/RB40 compared to that for neat oil at $0.128 \mathrm{Nm}$ and that for mineral oil at $0.144 \mathrm{Nm}$.

\section{Flash Temperature Parameter}

The FTP values for blends of RBD palm olein and mineral oil are shown in Figure $5 b$. The figure

Figure 5. (a) Wear scar diameter and coefficient of friction; (b) friction torque and flash temperature parameter of (RBD) palm olein blend samples. 
shows that RBD palm olein and mineral oil blends escalate the FTP values as compared to neat RBD palm olein and mineral oils, which can be attributed to the fact that the FTP depends on the applied load and WSD. Since the applied load is constant, thus lower the WSD increases the FTP (Shahabuddin et al., 2013). The highest FTP value was 140.1 for the E60/RB40 blend compared to the 71.4 for neat RBD palm olein and 93.2 for the mineral engine oil.

\section{Design of Experiments (DOE)}

The resulting optimisation ratio was obtained according to the DOE procedure, which gives the blend of $\mathrm{E} 53.11 \%$ and RB46.89\% (i.e., E53.11/ RB46.89). The results are shown in Figure 6. The tribological performance offered by the oil blends (WSD, coefficient of friction, friction torque, and flash temperature parameter) was compared against the performance of the mineral engine oil (SAE 10W-30), which is used commercially. $10 \mathrm{ml}$ of the lubricant was used for each of the four ball tribotester tests and $1000 \mathrm{ml}$ of lubricant was used for the air compressor test.

The diagrams for normal probability's confidence levels of $95 \%$ as a variation between experimental and theoretical responses for all tests FTP, FT, COF, and WSD data of blends for RBD palm olein and mineral engine oils (E80 / RB20, E60 / RB40, E40/RB60, E20/RB80, and E100) for choosing the optimal blends are indicated in Figure $6 e$. This figure shows that the WSD, COF, FT, and FTP average values based on the tests lay in the required confidence space (Şolea et al., 2013). Thus, all checkpoints did not surpass the existing safe regions. A slight variation in measured and predicted tribology feature checkpoint values, proving the optimal formulation validity, is illustrated in Figure 6e.

\section{Wear (weight) Losses}

The results of the measured amount of the wear weight losses for the moving parts in the air compressor system were plotted as a comparison amount for the oil samples as shown in Figure 7. This figure provides an illustration of the weight loss (wear) following $60 \mathrm{hr}$ of operation, for neat RBD palm olein, RBD palm olein-mineral oil blend and mineral engine oil (E100). The figure shows that the minimum metallic weight loss value was of the RBD palm olein - mineral oil blend (E53.11/ RB46.89) was $0.048 \mathrm{~g}$ litre $^{-1}$ compared to that of mineral engine oil with $0.09 \mathrm{~g} \mathrm{litre}^{-1}$, and that of neat RBD palm olein (E0/RB100) with $1.96 \mathrm{~g}_{\text {litre }}^{-1}$ (Masjuki and Maleque, 1996).

The aforementioned phenomena may be explained through the use of blended vegetable and mineral oil as the boundary lubricant between the contact movable parts such as piston rings and cylinder liner. It decreases weight loss (wear) because it contains saturated fatty acid that combines with bare metallic surfaces to create a metallic soap. The enhanced lubricating oil properties that contain the substances are caused by adsorption layers (Masjuki and Maleque, 1996).

\section{Cylinder Surface Temperatures}

The average temperatures of the two cylinder surfaces during the $360 \mathrm{~min}$ of daily continuous operation time were plotted as shown in Figure 8. This figure shows the comparison of the cylinder surface temperatures during the 360 min of daily continuous operation time of the neat RBD palm olein, blend of RBD palm olein with mineral oil, and the neat mineral engine oil. After $30 \mathrm{~min}$ of testing, the figure indicates that RBD palm olein-mineral engine oil blend's cylinder surface temperature values (E53.11/RB46.89) were lower than those of the mineral engine oil's cylinder surface temperature values (E100).

The higher cylinder surface temperature values were obtained for neat RBD palm olein. Moreover, from the figure it may be observed that the cylinder surface temperatures value after the $300 \mathrm{~min}$ appears stable for all tested samples. As indicated in Figure 8, it may be inferred that RBD palm olein-mineral oil's blending process reduces the cylinder surface temperature values, as a result of reduce friction between the cylindrical surface and piston rings, as well as in other movable parts when E53.11/RB46.89 is used for lubrication. The blended RBD palm olein with mineral oil (E53.11/ RB46.89) shows about 5.4\% maximum reduction in the cylinder surface temperature compared with the neat RBD palm olein and $1.7 \%$ compared with the mineral engine oil.

\section{CONCLUSION}

The inferences drawn from the above study are presented below:

1. The chosen vegetable oil (neat RBD palm olein and the blends of RBD palm olein with mineral oil) showed good reliability with regard to viscosity requirements since the outcomes for all viscosities after evaluating the ecofriendly vegetable oil met the viscosity grade requirement (ISO VG32).

2. The blending process leads to reduction in the values of WSD, friction torque and coefficient of friction, metallic particle lost weight, and cylinder surface temperature and increase in the value of flash temperature parameter compared to the values for the neat RBD palm olein and mineral engine oil. 


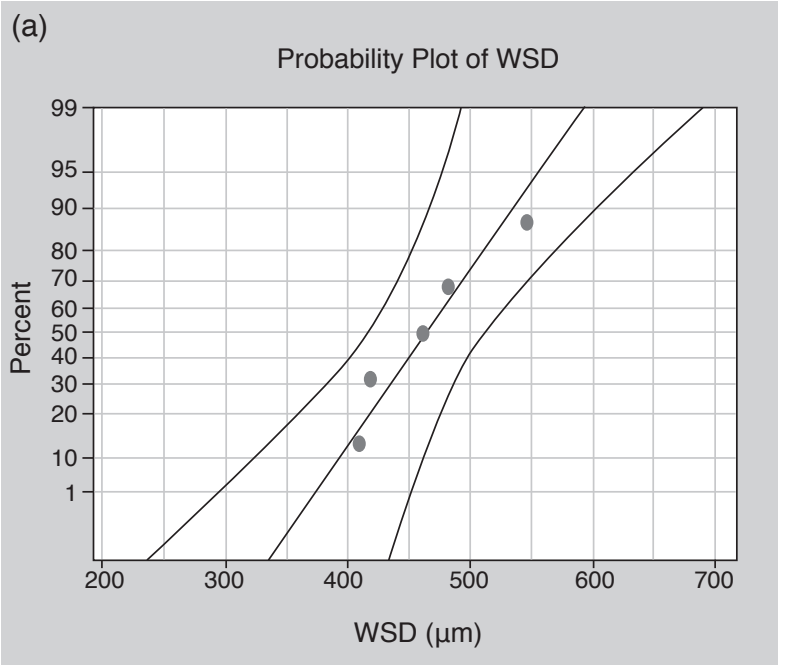

(c)

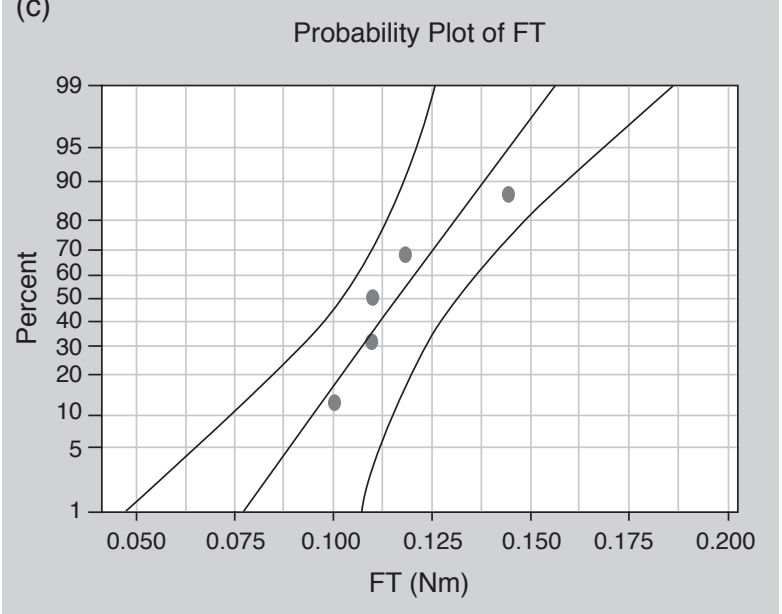

(b)

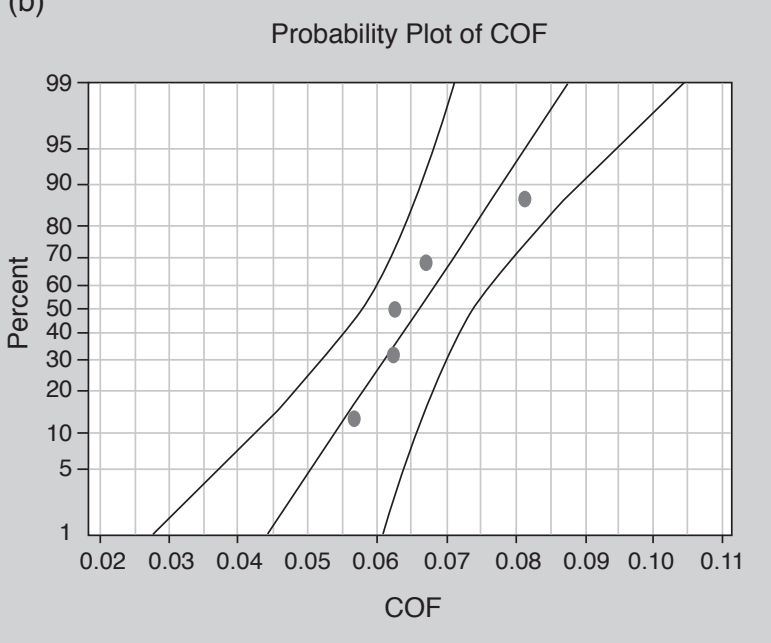

(d)

Probability Plot of FTP

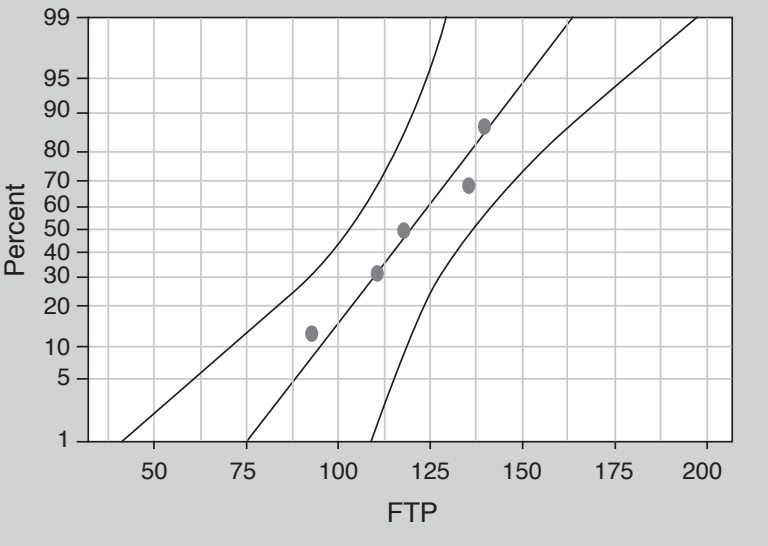

(e)

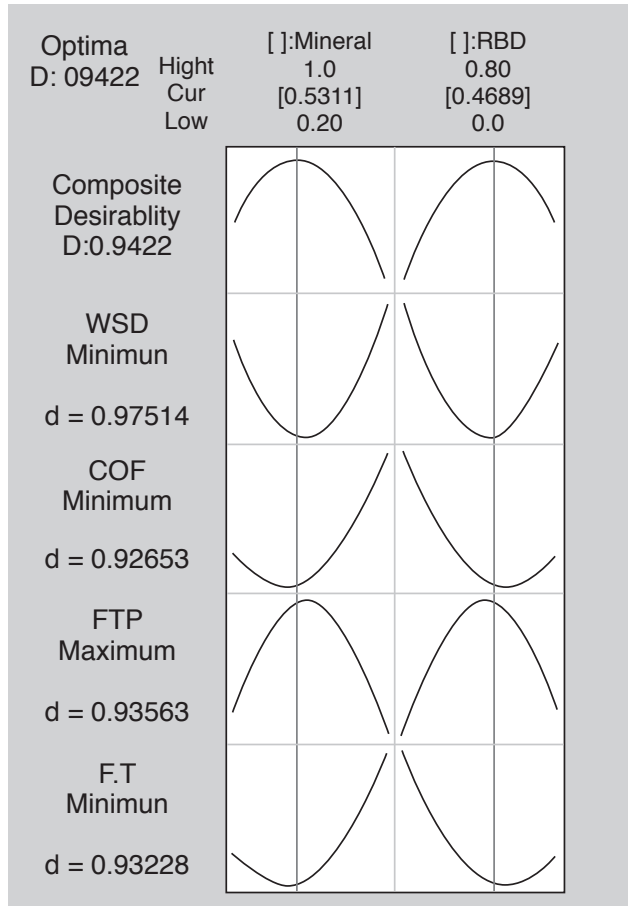

Figure 6. Normal probability plot for refined, bleached and deodorised (RBD) palm olein blends of (a) wear scar diameter; (b) coefficient of friction; (c) friction torque; (d) flash temperature parameter and (e) optimisation plot. 


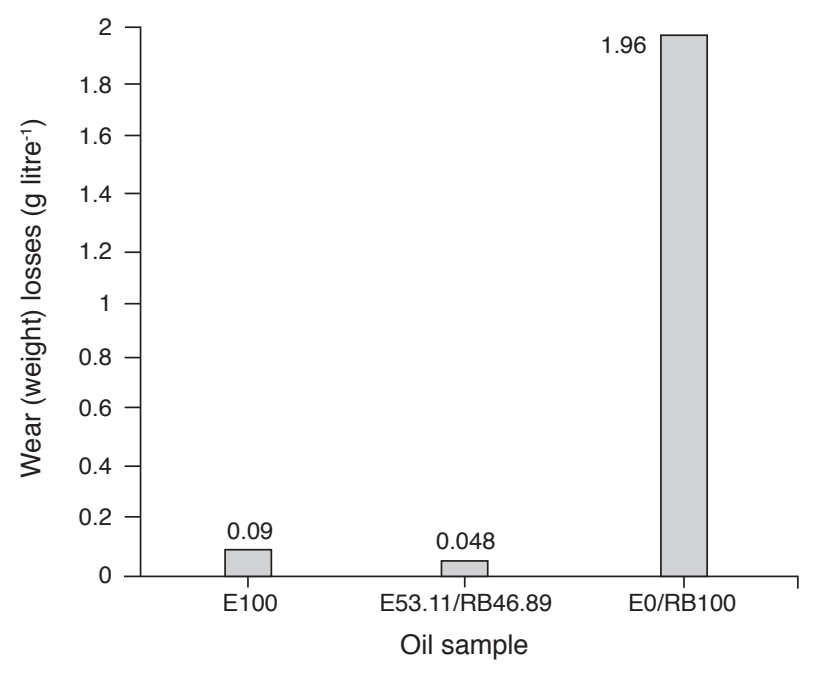

Figure 7. Wear (weight) losses for the oil samples.

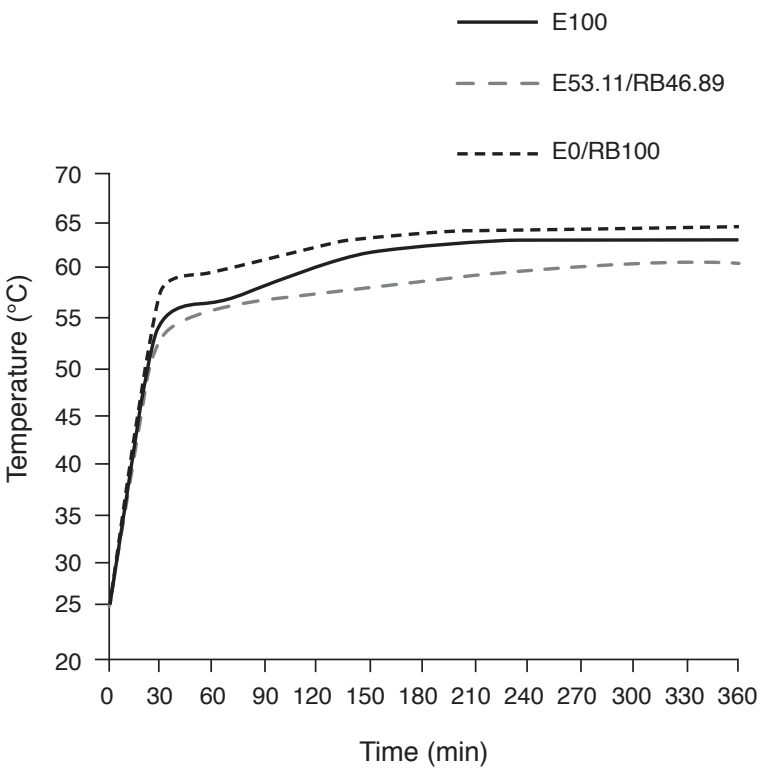

Figure 8. Average temperatures of the surface cylinder with respect to the time for the oil samples.

3. From the study, it can be recommended that the blend RBD palm olein with mineral engine oil (E53.11/RB46.89) could be an effective alternative bio-lubricant as it showed no negative impact on wear and offered a good performance as a lubricant.

\section{ACKNOWLEDGEMENT}

The authors are highly grateful to the Faculty of Mechanical Engineering and Research Management Centre, Universiti Teknologi Malaysia for their support in completing this study.

\section{REFERENCES}

BARTZ, W J (2006). Eco tribology: environmentally acceptable tribological practices. Tribol Int., 39(8): 728-733.

DUZCUKOGLU, $\mathrm{H}$ and ŞAHIN, O S (2010). Investigation of wear performance of canola oil containing boric acid under boundary friction. Tribology Transactions, 54: 57-61.

GOLSHOKOUH, I; SYAHRULLAIL, S; ANI, F N and MASJUKI, H H (2014). Investigation of palm fatty acid distillate oil as an alternative to petrochemical based lubricant. J. Oil Palm Res. Vol. 26 (1): 25-36.

HUSNAWAN, M; SAIFULLAH, M G and MASJUKI, H H (2007). Development of friction force model for mineral oil basestock containing palm olein and antiwear additive. Tribology International, 40 (1): 7481.

ING, C T; MOHAMMED RAFIQ, A K; AZLI, Y and SYAHRULLAIL, S (2012). The effects of temperature on the tribological behavior of RBD palm stearin. Tribology Transactions, 55(5): 539-548.

JABAL, M H; ANI, F N and SYAHRULLAIL, S (2014). The tribological characteristic of the blends of RBD palm olein with mineral oil using four-ball tribotester. Jurnal Teknologi, 69 (6): 11-14.

MASJUKI, H H (1992). Effect of palm oil diesel on the boundary lubricated wear of cast irons. Jurnal Institusi Jurutera Malaysia, 49: 5-12.

MASJUKI, H H and MALEQUE, M A (1996). Wear, performance and emissions of a two-stroke engine running on palm oil methyl ester blended lubricant. J. Engineering Tribology, 210 (4): 213-219.

MASJUKI, H H; KALAM, M A; NURUL, M F; JAYED, $\mathrm{M} \mathrm{H}$; LIAQUAT, A $\mathrm{M}$ and VARMAN, $\mathrm{M}$ (2011). Environmentally friendly bio-lubricant lubricity testing. Proc. of the Clean Energy and Technology (CET). 27-29 June 2011. Kuala Lumpur, Malaysia. IEEE: 140-144.

MASJUKI, H H and MALEQUE, M A (1997). Investigation of the anti-wear characteristics of palm oil methyl ester (POME) contaminated with lube oil using a four-ball machine of IP239 Standard. Wear, 206: 179-186.

MOHAMMED HASSAN; FARID NASIR ANI and S SYAHRULLAIL (2015). Tribological features of refined, deodorized and bleached palm olein with mineral oil blend. Tribology Transaction, 59 (4): 671678. 
PETLYUK, A M and ADAMS, R J (2004). Oxidation stability and tribological behavior of vegetable oil hydraulic fluids. Tribology Transactions, 47(2): 182187.

REWOLINSKI, C (1985a). Sunflower oil diesel fuel: lubrication system contamination. J. Amer. Oil Chem. Soc. 62(7): 1120-1124.

REWOLINSKI, C (1985b). Sunflower oil diesel fuel: engine wear implications. J. Amer. Oil Chem. Soc. 62(11): 1598-1599.

SHAHABUDDIN, M; MASJUKI, H H; KALAM, M A; BHUIYA, M M K and MEHAT, H (2013). Comparative tribological investigation of biolubricant formulated from a non-edible oil source (Jatropha oil). Industrial Crops and Products, 47: 323330.

SINGH, H and GULATI, I (1991). Tribological behaviour of base oils and their separated fractions. Wear, 147(1): 207-218.
SIVASANKARAN, G A; BRI, R P S; JAIN, V K and GUPTN, M (1988). Jojoba-based two stroke gasoline engine lubricant. Tribology Int., 21(6): 327-333.

ŞOLEA, I C; DELEANU, I and GEORGESCU, C (2013). Evaluation of olive oil as lubricant with the help of four-ball tester. Mechanical Testing and Diagnosis. 3: 40-48.

WAN NIK, W B; MALEQUE, M A; ANI, F N and MASJUKI, H H (2007). Experimental investigation on system performance using palm oil as hydraulic fluid. Industrial Lubrication and Tribology, 59 (5): 200208.

WAN NIK, W B; MASJUKI, H H and GIAP, S E (2005). Rheology of bio-edible oils according to several rheological models and its potential as hydraulic fluid. Industrial Crops and Products, 22(3): 249-255.

WAN NIK, W B; ZULKIFLI, F; AYOB, A F; KADER, A S A and WARIKH, A R M (2013). Rheology study of plant oil for marine application. Procedia Engineering, 68: 138-144. 